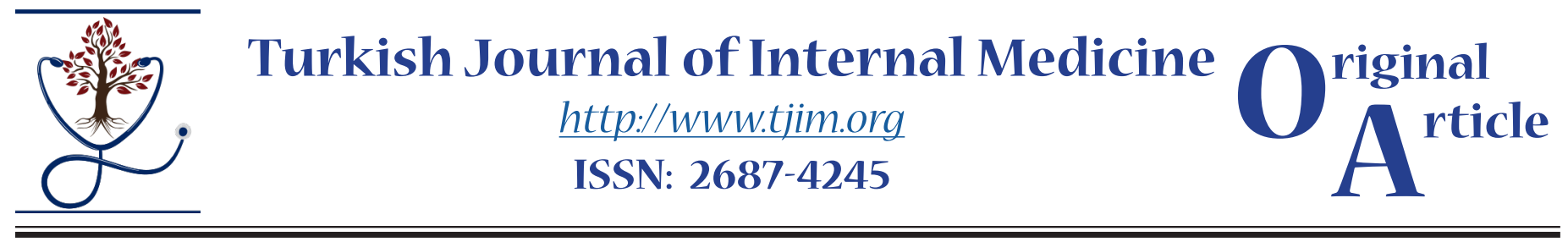

\title{
Serum Cystatin C Measurement in Lupus Nephritis Patients: Its Correlation with Clinical and Histopathological Findings
}

\author{
İbrahim Akdağ ${ }^{1}$, (D) Alparslan Ersoy ${ }^{2}$ (D) \\ ${ }^{1}$ Division of Nephrology, Dışkapı Yıldırım Beyazıt Training and Research Hospital, Ankara, Turkey \\ ${ }^{2}$ Division of Nephrology, Department of Internal Medicine, Uludag University Faculty of Medicine, Bursa, Turkey
}

\begin{abstract}
Introduction. To investigate the relationship between serum cystatin C levels and disease activity, renal function test, and histopathological findings in patients with lupus nephritis that did not receive any previous treatment.
\end{abstract}

Methods. 20 patients with lupus nephritis and 20 healthy subjects were included in the study. Before initiation of spesific treatment, clinical and laboratory findings including serum creatinine, cystatin $\mathrm{C}$, daily proteinuria and Cockcroft and Gault (C-G) and Modification of Diet in Renal Disease (MDRD) study equation in adults creatinine clearances $(\mathrm{CrCl})$, as well as histopathological activity and chronicity indices and systemic lupus erythematosus disease activity index (SLEDAI) were evaluated.

Results.Serum creatinine, cystatin C, C-G and MDRD CrCls in the patients with lupus nephritis and controls were comparable. Both serum creatinine and cystatin $\mathrm{C}$ levels positively correlated with activity index and SLEDAI. There was a negative correlation between $\mathrm{C}-\mathrm{G} \mathrm{CrCl}$ with activity index and MDRD $\mathrm{CrCl}$ with activity index and SLEDAI.

Conclusions.Our findings suggest that in lupus nephritis measuring the cystatin $\mathrm{C}$ level before renal biopsy is performed can not provide a more beneficial predictor than creatinine.

Keywords: Creatinine clearance, creatinine, cystatin C, systemic lupus erythematosus.

\section{Introduction}

Systemic lupus erythematosus (SLE) is a chronic inflammatory disease of unknown cause which can affect the skin, joints, kidneys, lungs, nervous system, serous membranes and/or other organs of the body. Renal involvement in SLE is a common manifestation and a story predictor of poor outcome. ${ }^{1,2}$ Renal biopsy plays an important role in the diagnosis and staging of lupus nephritis It also guides the appropriate selection of treatment especially for high-risk patients. ${ }^{3}$ Glomerular dysfunction is usually more prominent and clinically important than tubular dysfunction in 
lupus nephritis. Ideally, glomerular filtration rate (GFR) should be determined with a method that is convenient, inexpensive, and accurate. Serum creatinine is the most widely used screening test to detect abnormalities of glomerular filtration. ${ }^{4}$ It is affected not only by GFR, but also by age and muscle mass. ${ }^{5}$ GFR can be estimated from serum creatinine using Modification of Diet in Renal Disease (MDRD) or Cockroft and Gault (C-G) equations. ${ }^{5,6}$ However, these equations have not been generalizable across all clinical presentation. For example, the MDRD equation, derived with chronic kidney disease patients, underestimated GFR in healthy persons by $29 \%{ }^{7}$ All methods for estimating GFR have their strengths and limitations.

Human cystatin $\mathrm{C}$ is a 132 -amino-acid, $13-\mathrm{kd}$ cysteine protease inhibitor, which is produced by all nucleated cells and modulated by intracellular protein catabolism. Its endogenous production rate is unaltered during inflammatory processes. ${ }^{8}$ Serum cystatin $C$ reliably detects renal dysfunction in patients with various renal disease including SLE. ${ }^{9,10}$ Cystatin $\mathrm{C}$ is a biomarker with significant advantages over serum creatinine in patients with extremes in muscle mass, weight, age, and other areas where estimating equations using creatinine have well documented limitations. ${ }^{11}$ Available data on cystatin $C$ in lupus nephritis are limitedThere are few studies investigating the relationship of new kidney biomarkers with disease activity and damage in lupus nephritis. ${ }^{12-16}$ The aim of this study was to investigate the relationship between serum cystatin $\mathrm{C}$ levels with disease activity, other renal function tests, clinical and histopathological findings in patients with lupus nephritis who did not receive any previous treatment.

\section{Methods}

Patients hospitalized in our clinic between 1999 and 2003 with newly diagnosed SLE not being treated with corticosteroids and/or immunosuppressive therapy, were analyzed. Patients with bleeding diathesis, single kidney, acute urinary infection or rapidly progressive glomerulonephritis were excluded from the study. The study was performed in accordance with the Helsinki Human Rights protocol. Written informed consents were obtained from all patients.
SLE was diagnosed according to the 1982 classification criteria of SLE by the American College of Rheumatology (ACR). ${ }^{17}$ A total of 20 caucasion SLE cases who had proteinuria or/and hematuria were included in the study. Control subjects were derived from our internal medicine outpatient clinics and twenty healthy individuals evaluated. All control subjects underwent a detailed examination and they had normal findings.

Before the initiation of treatment, complete urine analysis, daily urine protein excretion, whole blood count, coagulation tests, erythrocyte sedimentation rate, serum urea, creatinine, electrolytes, total protein, albumin, AST and ALT levels, serum protein electrophoresis, C-reactive protein (CRP), immunoglobulin levels, antinuclear antibody (ANA), anti-double-strain DNA (anti-dsDNA), complement (C) 3 and C4 were measured for all patients.

Percutaneous renal biopsy was performed to these patients using a 14-16 G Magnum bard biopsy needle guided with ultrasonography. Presence of 10 glomeruli and 2 vessels in the biopsy materials was considered as sufficient material. Biopsy materials were treated with hematoxylin-eozin (HE), periodical acid-Schiff (PAS), Masson Trichromium (MT), periodical acid silver methenamine (PAS-M) dyes. All biopsies were evaluated by light microscopy and immunofluorescence. According to the International Society of Nephrology/Renal Pathology Society Classification (ISN/RPS) 2003 histopathological classification, there were mesangial proliferative lupus nephritis in 6 patients (Class II), focal lupus nephritis in 6 patients (Class III), diffuse lupus nephritis in 6 patients (Class IV) and membranous lupus nephritis in 2 patients (Class V). ${ }^{18,19}$ Then, each biopsy was calculated for activity and chronicity indices using a semi quantitative ranking system. ${ }^{20,21}$ In these indices glomerular and tubulointerstitial lesions were ranked as 0 (no lesions), 1, 2 or $3(+)$ semi quantitatively. As activity indices glomerular hypercellularity, leukocyte exudation, karyorrhexis, fibrinoid necrosis, cellular crescent, hyaline collection and interstitial cellular infiltration was evaluated. The total score was determined using a 24 point scale. For chronicity indices glomerular sclerosis, fibrous crescent, tubular atrophy and interstitial fibrosis were evaluated. The total score was determined 
using a 12 point scale.

The SLE disease activity index (SLEDAI) was also determined from the clinical and laboratory data of these cases. Psychosis, organic brain syndrome, findings associated with vision, cranial nerve damage, lupus headache, paralysis and presence of vasculitis 8 points each; arthritis, myositis, cast, proteinuria and pyuria 4 points each; new malar rash, alopecia, mucosal lesions, pleurisy, pericarditis, reduced complement and increased anti-dsDNA 2 points each; and fever, thrombocytopenia, leucopenia were assigned 1 point each. ${ }^{22}$

Creatinine clearance $(\mathrm{CrCl})$ was calculated with C-G [(140- age) (body weight in $\mathrm{kg}) / 72 \mathrm{x}$ serum creatinine $(\mathrm{mg} / \mathrm{dL})$ (0.85 if patient was female) ${ }^{6}$ and MDRD [186 x [serum creatinine $(\mathrm{mg} / \mathrm{dL})]^{-1.154} \times$ [age] $^{-0.203} \times(0.742$ if patient was female) $]^{5}$ prediction equation for adults formulas. Serum samples taken before biopsies were kept at $-55{ }^{\circ} \mathrm{C}$ in a deep freezer. Serum cystatin $\mathrm{C}$ levels were measured in a BNII nephelometer (Dade Behring Inc, Germany) using a particleenhanced immunonepholometric assay ( $\mathrm{N}$ Latex Cystatin-C). Normal ranges for male and female were 0.57 to $0.96 \mathrm{mg} / \mathrm{L}$ and 0.50 to $0.96 \mathrm{mg} / \mathrm{L}$, respectively.

All statistical analysis was done with statistical programme of SPSS 13.0 software (SPSS Inc., Chicago, IL, USA). Clinical and laboratory data were expressed as mean \pm SD. By taking variability skewness (a3) and curtosis (a4) values into account the non-parametric and parametric test options were evaluated. The numerical variables of patients with lupus nephritis and controls were compared with unpaired student $t$ test or Mann-Whitney $\mathrm{U}$ test. For comparisons of ratios in both groups, Fisher exact test was used. Correlations between numerical variables were tested by the Pearson rank correlation test ( $r=$ correlation coefficient). $p<0.05$ was considered statistically significant.

\section{Results}

The age, gender distribution, serum creatinine, cystatin $\mathrm{C}$ and $\mathrm{C}-\mathrm{G}$ and $\mathrm{MDRD} \mathrm{CrCl}$ in the patients with lupus nephritis and controls were similar ( $p>0.05$, Table 1). 12 patients $(60 \%)$ had malar rash, 7 (35\%) discoid rash, 7 (35\%) photosensitivity, 6 (30\%) oral ulcers, 9 (45\%) arthropathy, 2 (10\%) serositis, 1 (5\%) neurological, $8(40 \%)$ hematological disorder, $20(100 \%)$ renal disorder, 16 (80\%) immunologic disorder and $18(90 \%)$ abnormal titer of ANA. In all patients with lupus nephritis, CRP levels were $0.86 \mathrm{mg} /$ dL (range: 0.5-3.8), activity indices 6.1 (0-16), chronicity indices 0.7 (0-3) and SLEDAI 14.7 (5-30). The correlation analysis between all parameters of 20 lupus nephritis patients was performed (Table 2).

The serum creatinine values negatively correlated with C-G and MDRD $\mathrm{CrCls}$ and positively correlated with cystatin C (Figure 1a), activity indices and SLEDAI. There was a positive relationship between serum cystatin $\mathrm{C}$ with activity index (Figure $1 \mathrm{~b}$ ) and SLEDAI (Figure 1c), but not $\mathrm{C}-\mathrm{G}$ and $\mathrm{MDRD} \mathrm{CrCl}$. There was a negative correlation between C-G $\mathrm{CrCl}$ with activity index and MDRD $\mathrm{CrCl}$ with

Table 1. The comparison of demographic features and renal function parameters in patients with lupus nephritis and controls*

\begin{tabular}{lcc}
\hline & Lupus nephritis (n:20) & Control (n:20) \\
\hline Age (year) & $32.6 \pm 11.1$ & $29.5 \pm 7.3$ \\
Gender (male/female) & $2 / 18$ & $2 / 18$ \\
BMI (kg/m $\mathbf{m}^{\mathbf{2}}$ & $23.0 \pm 3.4$ & $23.1 \pm 4.3$ \\
Creatinine (mg/dL) & $0.85 \pm 0.3$ & $0.79 \pm 0.1$ \\
Cystatin C (mg/L) & $0.97 \pm 0.5$ & $0.76 \pm 0.08$ \\
C-G CrCl (mL/min) & $100.1 \pm 31$ & $112 \pm 35$ \\
MDRD CrCl (mL/min) & $93 \pm 28$ & $109 \pm 29$ \\
\hline
\end{tabular}

BMI: body mass index, CrCl: creatinine clearence, C-G: Cockcroft and Gault, MDRD: Modification of Diet in Renal Disease study equation in adults. $* \mathrm{p}>0.05$ 
Table 2. The correlations of clinical and histopathological findings with renal function parameters in the lupus nephritis patients

\begin{tabular}{llcccccc}
\hline & & \multirow{2}{*}{ Cystatin C } & $\begin{array}{c}\text { C-G } \\
\text { CrCl }\end{array}$ & $\begin{array}{c}\text { MDRD } \\
\text { CrCl }\end{array}$ & $\begin{array}{c}\text { Activity } \\
\text { Index }\end{array}$ & $\begin{array}{c}\text { Chronicity } \\
\text { index }\end{array}$ & SLEDAI \\
\hline Creatinine & $\mathrm{r}$ & 0.686 & -0.792 & -0.827 & 0.547 & 0.029 & 0.526 \\
& $\mathrm{p}$ & 0.001 & 0.001 & 0.001 & 0.013 & 0.902 & 0.017 \\
\cline { 2 - 7 } Cystatin C & $\mathrm{r}$ & & -0.434 & -0.387 & 0.459 & 0.028 & 0.489 \\
& $\mathrm{p}$ & & 0.056 & 0.09 & 0.042 & 0.907 & 0.029 \\
\cline { 2 - 7 } C-G CrCl & $\mathrm{r}$ & & & 0.876 & -0.573 & 0.085 & -0.309 \\
& $\mathrm{p}$ & & & 0.001 & 0.008 & 0.721 & 0.186 \\
\cline { 2 - 7 } MDRD & $\mathrm{r}$ & & & & -0.497 & 0.155 & 0.457 \\
CrCl & $\mathrm{p}$ & & & & 0.026 & 0.515 & 0.043 \\
\hline
\end{tabular}

CrCl: creatinine clearance, C-G: Cockcroft and Gault, MDRD: Modification of Diet in Renal Disease study equation in adults, SLEDAI: Systemic lupus erythematosus disease activity index.

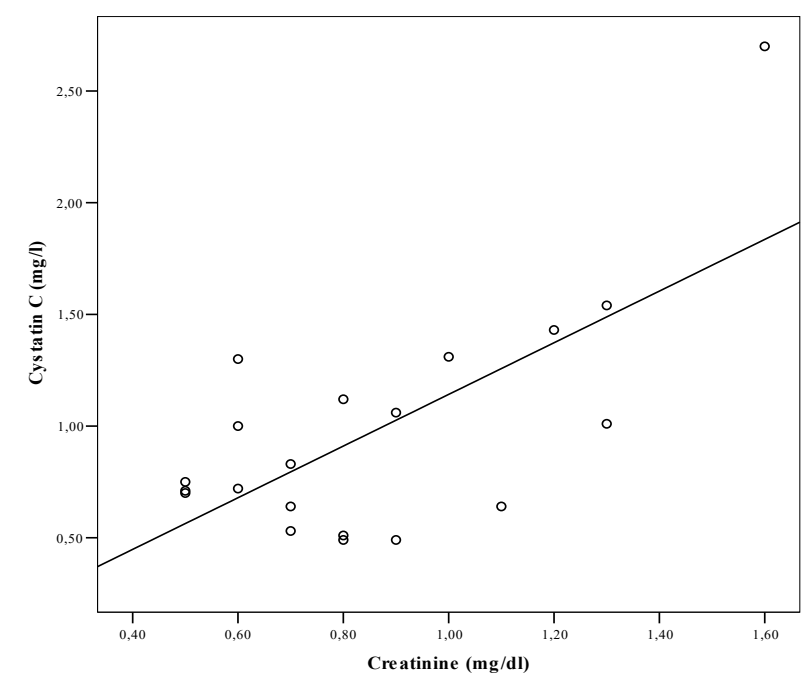

c

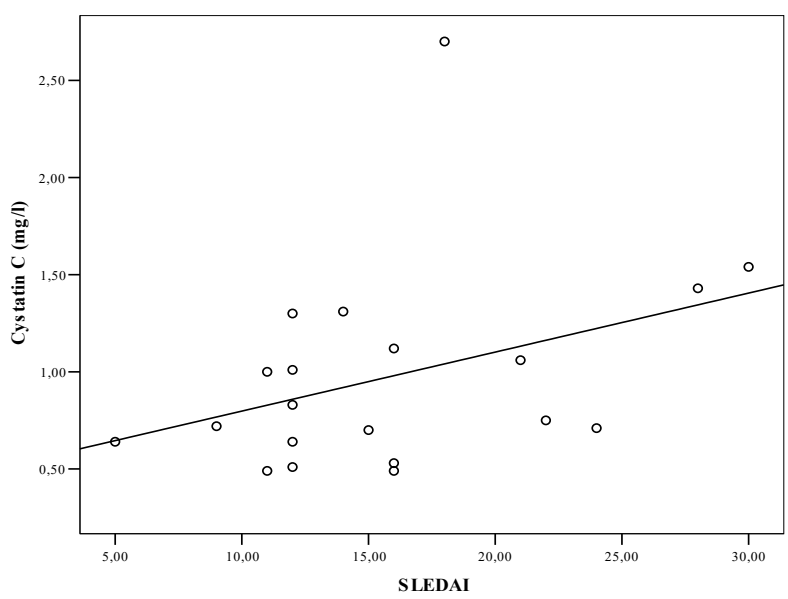

b

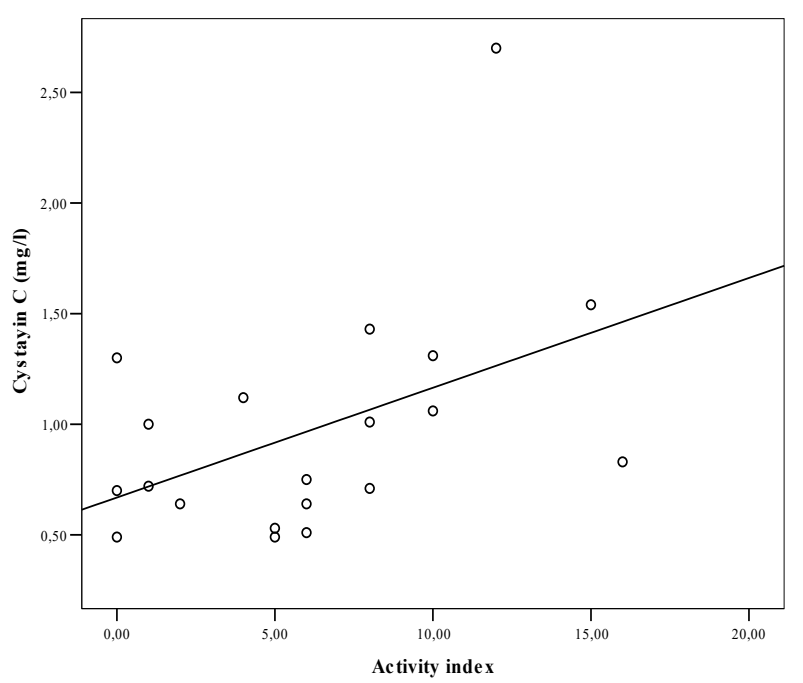

Figure 1. Correlations between serum Cystatin $C$ with creatinine (a) activity index (b) and SLEDAI (c) in the patients with lupus nephritis 
activity index and SLEDAI. These renal functions parameters did not correlate with CRP levels and daily protein excretions.

\section{Discussion}

There is a strong correlation between serum creatinine and cystatin C. Cystatin $\mathrm{C}$ has been proposed as an indicator of GFR with a higher diagnostic efficacy than serum creatinine. ${ }^{23,24}$ Its concentration appears to be independent of gender, age, nutrition, medications or body mass. ${ }^{25,26}$ However, in at least one general population study, cystatin $C$ was found to be influenced by several factors age, gender body size and cigarette smoking independent from $\mathrm{CrCl}^{27}$ Recent studies have shown that serum cystatin $\mathrm{C}$ can be used as an accurate marker of GFR in diabetic and nondiabetic patients. ${ }^{9,10,23}$ However, $\mathrm{C}-\mathrm{G} \mathrm{CrCl}$ remained the best marker of renal function in diabetic patients when compared $\mathrm{Cr}$ EDTA and other parameters such as cystatin C and creatinine. ${ }^{10} \mathrm{~A}$ large number of studies favor cystatin $\mathrm{C}$ over serum creatinine for estimation of GFR, but not all. ${ }^{28}$

A study that was performed in 226 patients with various nephropaties except SLE showed that serum cystatin $C$ was at least as efficacous as serum creatinine in detecting a reduced GFR as measured by $\mathrm{CrCl}^{29}$ Serum cystatin $\mathrm{C}$ levels were found to be higher in SLE patients than in healthy controls and in SLE patients with a history of lupus nephritis than those without a history of nephritis. In the same study, serum cystatin C correlated positively with serum creatinine, and inversely to renal measures such as the modified $\mathrm{C}-\mathrm{G}$ and MDRD equations. In the multivariate analysis, age, serum creatinine and high-sensitivity CRP was independently associated with serum cystatin C. ${ }^{30}$ Reciprocal of serum cystatin $\mathrm{C}$ also was well correlated with GFR obtained by the standard sodium thiosulfate clearance test [C(Thio)]. A study of 212 patients with various renal diseases all histopathologically proven by renal biopsy showed that no factors other than $\mathrm{C}$ (Thio) affected serum cystatin C concentrations, whereas age, SLE, dosage of daily prednisolone and CRP affected beta 2-microglobulin concentrations, and both gender and dosage of daily prednisolone affected serum creatinine concentrations. ${ }^{9}$ It is unclear whether glucocorticoid therapy affects serum cystatin C levels in lupus nephritis patients. The recent study have not observed such interference in the lupus nephritis patients submitted to corticotherapy. ${ }^{31}$ The measurements of our patients with SLE were taken at the time of diagnosis before specific treatment was initiated.

One of the main purposes of GFR estimation in clinical practice is to screen for patients with mild renal disfunction. A recent study in patients with different stages of chronic kidney disease indicated that serum cystatin $\mathrm{C}$ was reliable marker of GFR in patients with decreased GFR. ${ }^{32}$ Serum cystatin $\mathrm{C}$ was find more efficacious than serum creatinine and $\mathrm{CrCl}$ in detecting reduced GFR in type 2 diabetic patients. ${ }^{33}$ The serum cystatin $\mathrm{C}$ concentrations can be determined from a single blood sample making this parameter a reliable screening measure for identifying patients with subclinical renal failure. Tomino et al. ${ }^{34}$ showed that the level of serum cystatin $C$ were statistically correlated with the prognostic stages of patients with IgA nephropathy prior to renal biopsy in contrast with serum creatinine and $\mathrm{CrCl}$. The present study did not suggest that cystatin $C$ could be more useful to detect impaired renal function in lupus nephritis, although the size of lupus nephritis groups were too small to make any definite conclusion. Indeed, the use of serum creatinine-based equations rather than GFR as the gold standart in this study limits its conclusions. Also we did not compare the renal function parameters of patients in different stages due to the small number of patients we studied in each class. In a large case-control study including 334 patients with active lupus nephritis, 255 patients with inactive lupus nephritis and 497 healthy individuals, estimated GFR cystatin-C (MDRD) and $\mathrm{C} 1 \mathrm{q}$ were superior to the conventional biomarkers urea, creatinine and estimated GFR creatinine in the diagnosis of active lupus nephritis. ${ }^{35}$ Although beta 2-microglobulin/serum creatinine index is a prognostic factor predicting active lupus, beta 2-microglobulin/cystatin C index has no added benefit in the assessment of renal activity in SLE. ${ }^{36}$

Although the aforementioned studies have tested the correlation between serum cystatin $\mathrm{C}$ and other renal function tests, most of these studies have not evaluated the relationship of renal markers with clinical and histapatological activity findings in patients with lupus nephritis. We studied 
the correlation between renal function tests with SLEDAI and histapathological activity indices. Serum cystatin $\mathrm{C}$, creatinine and $\mathrm{CrCl}$ equations correlated with activity indices and SLEDAI (except $\mathrm{C}-\mathrm{G} \mathrm{CrCl}$ ), but not chronicity indices. Confounding factors associated with cystatin C could lead to inaccurate GFR estimations in lupus nephritis patients. A recent study showed 19\% higher GFR at the same cystatin C level among kidney transplant recipients compared to native kidney disease patients. ${ }^{37}$ They suggested that the responsible mechanism could be increased cystatin $\mathrm{C}$ production from systemic inflammation or use of immunosuppression therapy in this population. Kidney dysfunction is known to be associated with elevations in inflammatory biomarkers. Knight et al. ${ }^{27}$ found that cystatin $\mathrm{C}$ was associated with $\mathrm{CRP}$ even after adjustment for $\mathrm{CrCl}$, implying that the protein cystatin $\mathrm{C}$ had some biologic link to inflammation. A recent study found that CRP and fibrinogen levels were linearly associated with quintiles of cystatin $\mathrm{C}$ in elderly. ${ }^{38} \mathrm{In}$ our study cystatin $C$ levels did not correlate with CRP levels in our untreated newly diagnosed lupus nephritis patients. SLE could influence serum cystatin $\mathrm{C}$, but its levels were comparable patients with lupus nephritis and healthy subjects. It has been reported associations between anti-CRP and and histopathological activity or disease activity in lupus nephritis. ${ }^{39}$

The results of recent studies on new serum and urine biomarkers in patients with SLE are promising. Among all urinary markers, urinary clusterin is better marker at predicting end-stage renal disease than others (albumin, beta 2-microglobulin, cystatin $\mathrm{C}$, kidney injury molecule-1, monocyte chemoattractant protein-1, calbindin, interleukin-18, neutrophil gelatinaseassociated lipocalin, trefoil factor 3, osteopontin, and glutathione S-transferase). Interestingly, elevation of urinary clusterin likely resulted from local over-expression in tubulointerstitial tissue. ${ }^{40}$ In other study, novel urinary cytokines and chemokines (urinary monocyte chemoattractant protein 1 and tumor necrosis factor-like weak inducer of apoptosis) possess higher correlation coefficients with renal damage than traditional serum or urinary markers (urinary alpha 1-microgrobulin, beta 2-microglobulin and serum C3, C4, creatinine, blood urea nitrogen and cystatin C) in lupus nephritis. ${ }^{41}$ There was a significant increase in serum cystatin $C$, urinary neutrophil gelatinase-associated lipocalin (UNGAL) and $\mathrm{N}$-acetyl-beta-D-glucosaminidase (UNAG) levels in adult SLE patients compared with controls. Serum cystatin $\mathrm{C}$ significantly correlated with the damage index, renal biopsy class and negatively with the serum albumin; UNGAL correlated with albuminuria and the level of nephritis and UNAG negatively correlated with serum albumin level. ${ }^{42}$

\section{Conclusions}

Cystatin $\mathrm{C}$ is an important endogenous filtration marker that is being considered as a potential replacement for serum creatinine. Measurement of serum cystatin $C$ level other than creatinine before renal biopsy in lupus nephritis patients did not provide more advantage for the prediction of histopathological activity index as well as SLEDAI. However, it is currently more expensive to measure cystatin $C$ than creatinine, so it is not widely used as a GFR marker in most of the countries. Further prospective studies should focus on whether serum cystatin $C$ correlates with long-term renal outcome better than chemical methods for assessing kidney function in patients with various renal diseases including SLE.

\section{Acknowledgement}

The authors dedicated this article to the memory of our colleague, Dr. Gulaydan Filiz, who also evaluated the pathological findings of this study and lost at the most productive age.

\section{Conflict of interest}

The authors declared that there are no potential conflicts of interest with respect to the research, authorship, and/or publication of this article.

\section{References}

1. Chonchol M, Shlipak MG, Katz R, Sarnak MJ, Newman Tahir H, Isenberg DA. Novel therapies in lupus nephritis. Lupus. 2005;14(1):77-82.

2. Croca SC, Rodrigues T, Isenberg DA. Assessment of a lupus nephritis cohort over a 30-year period. Rheumatology (Oxford). 2011 Aug;50(8):1424-30. doi: 10.1093/rheumatology/ker101.

3. Mittal B, Rennke H, Singh AK. The role of kidney biopsy in the management of lupus nephritis. Curr Opin Nephrol Hypertens. 2005 Jan;14(1):1-8.

4. Balow JE. Clinical presentation and monitoring of lupus 
nephritis. Lupus. 2005;14(1):25-30

5. Levey AS, Coresh J, Balk E, Kausz AT, Levin A, Steffes MW, Hogg RJ, Perrone RD, Lau J, Eknoyan G. National Kidney Foundation. National Kidney Foundation practice guidelines for chronic kidney disease: evaluation, classification, and stratification. Ann Intern Med. 2003 Jul 15;139(2):137-47.

6. Cockcroft DW, Gault MH. Prediction of creatinine clearance from serum creatinine. Nephron. 1976;16(1):3141.

7. Rule AD, Larson TS, Bergstralh EJ, Slezak JM, Jacobsen SJ, Cosio FG. Using serum creatinine to estimate glomerular filtration rate: accuracy in good health and in chronic kidney disease. Ann Intern Med. 2004 Dec 21;141(12):929-37.

8. Hermida J, Romero R, Tutor JC. Relationship between serum cystatin $C$ and creatinine in kidney and liver transplant patients. Clin Chim Acta. 2002 Feb;316(12):165-70.

9. Kazama JJ, Kutsuwada K, Ataka K, Maruyama H, Gejyo F. Serum cystatin C reliably detects renal dysfunction in patients with various renal diseases. Nephron. 2002 May;91(1):13-20.

10. Perlemoine C, Beauvieux MC, Rigalleau V, Baillet L, Barthes N, Derache P, Gin H. Interest of cystatin C in screening diabetic patients for early impairment of renal function. Metabolism. 2003 Oct;52(10):1258-64.

11. Ferguson TW, Komenda P, Tangri N. Cystatin C as a biomarker for estimating glomerular filtration rate. Curr Opin Nephrol Hypertens. 2015 May;24(3):295-300. doi: 10.1097/MNH.0000000000000115.

12. Madureira Silva MV, Moscoso-Solorzano GT, Nishida SK, Mastroianni-Kirsztajn G. Serum Beta 2-microglobulin/cystatin $C$ index: a useful biomarker in lupus nephritis? Nephron Extra. 2012 Jan;2(1):169-76. doi: 10.1159/000339643.

13. Chew C, Pemberton PW, Husain AA, Haque S, Bruce IN. Serum cystatin $C$ is independently associated with renal impairment and high sensitivity $\mathrm{C}$-reactive protein in systemic lupus erythematosus. Clin Exp Rheumatol. 2013 Mar-Apr;31(2):251-5.

14. Gheita TA, Abd El Baky AM, Assal HS, Farid TM, Rasheed IA, Thabet EH. Serum cystatin C, urinary neutrophil gelatinase-associated lipocalin and $\mathrm{N}$-acetylbeta-D-glucosaminidase in juvenile and adult patients with systemic lupus erythematosus: Correlation with clinical manifestations, disease activity and damage. Saudi J Kidney Dis Transpl. 2015 May-Jun;26(3):497-506. doi: 10.4103/1319-2442.157336.

15. Dong $X W$, Zheng $Z H$, Ding J, Luo $X$, Li ZQ, Li $Y$, Rong MY, Fu YL, Shi JH, Yu LC, Wu ZB, Zhu P. Combined detection of uMCP-1 and uTWEAK for rapid discrimination of severe lupus nephritis. Lupus. 2018 May;27(6):971-981. doi: 10.1177/0961203318758507.

16. Xu B, Zhang YM, Yang YW, Liu YS, Feng JF. Diagnostic performance of serum cystatin $\mathrm{C}$ and complement component 1q in lupus nephritis. Arthritis Res Ther. 2019 Dec 4;21(1):267. doi: 10.1186/s13075-019-2065-x.

17. Tan EM, Cohen AS, Fries JF, Masi AT, McShane DJ, Rothfield NF, Schaller JG, Talal N, Winchester RJ. The 1982 revised criteria for the classification of systemic lupus erythematosus. Arthritis Rheum. 1982 Nov;25(11):1271-7.

18. Chan TM. Histological reclassification of lupus nephritis. Curr Opin Nephrol Hypertens. 2005 Nov;14(6):561-6.
19. Weening JJ, D'Agati VD, Schwartz MM, Seshan SV, Alpers CE, Appel GB, Balow JE, Bruijn JA, Cook T, Ferrario F, Fogo AB, Ginzler EM, Hebert L, Hill G, Hill P, Jennette JC, Kong NC, Lesavre P, Lockshin M, Looi LM, Makino H, Moura LA, Nagata M. The classification of glomerulonephritis in systemic lupus erythematosus revisited. J Am Soc Nephrol. 2004 Feb;15(2):241-50.

20. Churg J, Bernstein J, Glassock RJ. Lupus nephritis. In: Churg J, Bernstein J, Glassock RJ, eds. Renal Diseases: Classification and Atlas of Glomerular Diseases. 2nd Ed. New York: Igaku-Shoin; 1995:151-6.

21. Austin HA 3rd, Muenz LR, Joyce KM, Antonovych TA, Kullick ME, Klippel JH, Decker JL, Balow JE. Prognostic factors in lupus nephritis. Contribution of renal histologic data. Am J Med. 1983 Sep;75(3):382-91.

22. Bombardier C, Gladman DD, Urowitz MB, Caron D, Chang $\mathrm{CH}$. Derivation of the SLEDAI. A disease activity index for lupus patients. The Committee on Prognosis Studies in SLE. Arthritis Rheum. 1992 Jun;35(6):630-40.

23. Keevil BG, Kilpatrick ES, Nichols SP, Maylor PW. Biological variation of cystatin C: implications for the assessment of glomerular filtration rate. Clin Chem. 1998 Jul;44(7):1535-9.

24. Massey D. Commentary: clinical diagnostic use of cystatin C. J Clin Lab Anal. 2004;18(1):55-60.

25. Finney H, Newman DJ, Price CP. Adult reference ranges for serum cystatin $C$, creatinine and predicted creatinine clearance. Ann Clin Biochem. 2000 Jan;37 ( Pt 1):49-59.

26. Vinge $\mathrm{E}$, Lindergård $\mathrm{B}$, Nilsson-Ehle $\mathrm{P}$, Grubb A. Relationships among serum cystatin $C$, serum creatinine, lean tissue mass and glomerular filtration rate in healthy adults. Scand J Clin Lab Invest. 1999 Dec;59(8):587-92.

27. Knight EL, Verhave JC, Spiegelman D, Hillege HL, de Zeeuw D, Curhan GC, de Jong PE. Factors influencing serum cystatin $C$ levels other than renal function and the impact on renal function measurement. Kidney Int. 2004 Apr;65(4):1416-21.

28. Zahran A, El-Husseini A, Shoker A. Can cystatin C replace creatinine to estimate glomerular filtration rate? A literature review. Am J Nephrol. 2007;27(2):197-205.

29. Herget-Rosenthal S, Trabold S, Pietruck F, Holtmann M, Philipp T, Kribben A. Cystatin C: efficacy as screening test for reduced glomerular filtration rate. Am J Nephrol. 2000 Mar-Apr;20(2):97-102.

30. Chew C, Pemberton PW, Husain AA, Haque S, Bruce IN. Serum cystatin $C$ is independently associated with renal impairment and high sensitivity $\mathrm{C}$-reactive protein in systemic lupus erythematosus. Clin Exp Rheumatol. 2013 Mar-Apr;31(2):251-5.

31. Silva MV, Moscoso Solorzano G, Nishida SK, Kirsztajn GM. Are serum cystatin $C$ levels influenced by steroid doses in lupus nephritis patients? J Bras Nefrol. 2011 JulSep;33(3):306-12.

32. Hojs R, Bevc S, Ekart R, Gorenjak M, Puklavec L. Serum cystatin $\mathrm{C}$ as an endogenous marker of renal function in patients with chronic kidney disease. Ren Fail. 2008;30(2):181-6. doi: 10.1080/08860220701810315.

33. Xia LH, Bing XG, An XT. Serum cystatin C assay for the detection of early renal impairment in diabetic patients. $\mathrm{J}$ Clin Lab Anal. 2004;18(1):31-5.

34. Tomino Y, Suzuki S, Gohda T, Kobayashi M, Horikoshi S, Imai H, Saito T, Kawamura T, Yorioka N, Harada T, Yasumoto Y, Kida H, Kobayashi Y, Endoh M, Sato H, Saito K. Serum cystatin $C$ may predict the prognostic 
stages of patients with IgA nephropathy prior to renal biopsy. J Clin Lab Anal. 2001;15(1):25-9.

35. Xu B, Zhang YM, Yang YW, Liu YS, Feng JF. Diagnostic performance of serum cystatin $\mathrm{C}$ and complement component 1q in lupus nephritis. Arthritis Res Ther. 2019 Dec 4;21(1):267. doi: 10.1186/s13075-019-2065-x.

36. Madureira Silva MV, Moscoso-Solorzano GT, Nishida SK, Mastroianni-Kirsztajn G. Serum Beta 2-microglobulin/cystatin C index: a useful biomarker in lupus nephritis? Nephron Extra. 2012 Jan;2(1):169-76. doi: 10.1159/000339643.

37. Rule AD, Bergstralh EJ, Slezak JM, Bergert J, Larson TS. Glomerular filtration rate estimated by cystatin C among different clinical presentations. Kidney Int. 2006 Jan;69(2):399-405.

38. Shlipak MG, Katz R, Cushman M, Sarnak MJ, StehmanBreen C, Psaty BM, Siscovick D, Tracy RP, Newman A, Fried L. Cystatin-C and inflammatory markers in the ambulatory elderly. Am J Med. 2005 Dec;118(12):1416.

39. Sjöwall C, Zickert A, Skogh T, Wetterö J, Gunnarsson I. Serum levels of autoantibodies against C-reactive protein correlate with renal disease activity and response to therapy in lupus nephritis. Arthritis Res Ther. 2009;11(6):R188. doi: 10.1186/ar2880.

40. Wu CY, Yang HY, Chien HP, Tseng MH, Huang JL. Urinary clusterin-a novel urinary biomarker associated with pediatric lupus renal histopathologic features and renal survival. Pediatr Nephrol. 2018 Jul;33(7):1189-1198. doi: 10.1007/s00467-018-3924-4.

41. Dong $X W$, Zheng $Z H$, Ding J, Luo $X$, Li ZQ, Li $Y$, Rong MY, Fu YL, Shi JH, Yu LC, Wu ZB, Zhu P. Combined detection of uMCP-1 and UTWEAK for rapid discrimination of severe lupus nephritis. Lupus. 2018 May;27(6):971-981. doi: 10.1177/0961203318758507.

42. Gheita TA, Abd El Baky AM, Assal HS, Farid TM, Rasheed IA, Thabet EH. Serum cystatin C, urinary neutrophil gelatinase-associated lipocalin and $\mathrm{N}$-acetylbeta-D-glucosaminidase in juvenile and adult patients with systemic lupus erythematosus: Correlation with clinical manifestations, disease activity and damage. Saudi J Kidney Dis Transpl. 2015 May-Jun;26(3):497-506. doi: 10.4103/1319-2442.157336. 